05.1

\title{
Влияние состава низкотемпературной азотной плазмы на гидрофильные и гидрофобные свойства покрытий на основе азотированного оксида титана
}

\author{
(C) А.Э. Муслимов ${ }^{1}$, М.Х. Гаджиев ${ }^{2}$, Р.М. Эмиров ${ }^{3}$, А.М. Исмаилов ${ }^{3}$, В.М. Каневский ${ }^{1}$ \\ ${ }^{1}$ Федеральный научно-исследовательский центр „Кристаллографиия и фоотоника“ РАН, Москва, Россия \\ ${ }^{2}$ Объединенный институт высоких температур РАН, Москва, Россия \\ ${ }^{3}$ Дагестанский государственный университет, Махачкала, Россия \\ E-mail: amuslimov@mail.ru
}

Поступило в Редакцию 6 мая 2021 г.

В окончательной редакции 18 июня 2021 г.

Принято к публикации 26 июня 2021 г.

Изучено влияние состава азотной плазмы на структурно-фазовый и элементный состав, топографию, механические и гидрофобные свойства покрытий на основе азотсодержащего оксида титана при натекании на образец в открытой атмосфере. Показано, что при одинаково высокой микротвердости порядка $25-27 \mathrm{GPa}$, контролируя состав азотной плазмы, можно формировать либо гидрофильные (контактный угол $73^{\circ}$ ), либо гидрофобные покрытия (контактный угол $120^{\circ}$ ).

Ключевые слова: гидрофобность, гидрофильность, диоксид титана, сапфир, низкотемпературная плазма, азот, контактный угол, микротвердость.

DOI: 10.21883/PJTF.2021.19.51511.18861

С развитием современных технологий существенно возросла потребность в соединениях и сплавах на основе титана. Наиболее востребованными среди них являются полиморфные модификации диоксида титана $\left(\mathrm{TiO}_{2}\right)$. Диоксид титана обладает высоким коэффициентом отражения и радиационной стойкостью [1] и может использоваться для защиты космических аппаратов от солнечного излучения. Модифицирование поверхности титановых имплантов путем нанесения слоев диоксида титана увеличивает биосовместимость и даже делает поверхность биоактивной [2]. Этот эффект может быть усилен азотным легированием диоксида титана. Например, авторами $[3,4]$ показано, что покрытия на основе нитридов, оксинитридов титана способны улучшить антитромбогенные свойства сердечно-сосудистых имплантатов. В этом случае одним из основных требований является высокая гидрофильность поверхности покрытия диоксида титана, что обусловливает ее сильное взаимодействие с кровью и более быструю остеоинтеграцию. Напротив, для применения диоксида титана в фотокаталитических процессах очистки [5] необходима полная иммобилизация поверхности очистителя по отношению к окружающей среде, например к молекулам воды. Поверхность диоксида титана должна быть максимально гидрофобной для минимизации адсорбции молекул воды и активного разложения молекул вредных веществ.

Следовательно, использование покрытий диоксида титана предполагается в самых различных условиях, и это диктует особые требования к их механическим свойствам. В работе [6] была продемонстрирована возможность получения сверхтвердых покрытий на основе диоксида титана путем обработки в низкотемпературной азотной плазме в открытой атмосфере. Что касается физического взаимодействия с жидкостями, то предполагается, что высокая сорбируемость ОН-групп поверхностью диоксида титана [7] делает ее гидрофильной. Однако на гидрофильные свойства наряду с химическими свойствами могут оказывать сильное влияние шероховатость, микроморфология поверхности [8] и, как оказалось, монофазность [9]. В работе [9] показано, что на близких по величине шероховатости поверхностях диоксида титана в зависимости от фазового состава могут реализоваться совершенно противоположные состояния: монофазная поверхность характеризуется высокой гидрофобностью, а в случае смешанного (анатаз, рутил) состава поверхность является гидрофильной. Помимо этого в ряде работ $[10,11]$ продемонстрировано влияние азотного легирования на гидрофильные и гидрофобные свойства покрытий на основе диоксида титана. Был получен интересный результат [10]: увеличение гидрофобности, достигнутое формированием специфической морфологии в виде наностержней рутиловой фазы, нивелировалось при увеличении концентрации азота выше $7 \%$, хотя до $3 \%$ наблюдалось только ее усиление. Для сплошных пленок диоксида титана смешанного фазового состава с низким уровнем легирования азотом (менее $0.1 \%)$ реализовалось гидрофильное состояние.

Приведенные литературные данные свидетельствуют о зависимости гидрофильных свойств пленок диоксида титана от структурно-фазового и примесного состава, шероховатости и морфологии поверхности. Как нам представляется, примененная в [6] методика обработки пленок титана в азотной плазме в открытой атмосфере при условии контроля ее состава может быть опти- 
мальной для формирования покрытий диоксида титана с заданными свойствами (гидрофильными или гидрофобными). При этом сохраняется требование к сверхвысокой твердости покрытия. В настоящей работе изучается влияние состава низкотемпературной азотной плазмы при натекании на образец в открытой атмосфере на структурно-фазовый и элементный состав, топографию, механические и гидрофобные свойства покрытий на основе азотированного оксида титана.

Пленка титана толщиной порядка $500 \mathrm{~nm}$ наносилась на подложки сапфира методом магнетронного осаждения [8]. Подложка предварительно прогревалась до $200^{\circ} \mathrm{C}$. Метод магнетронного осаждения способствовал улучшению адгезии между пленкой и подложкой благодаря высокой энергии ионов плазмы и плазменной активации поверхности. На следующем этапе образцы обрабатывались потоком низкотемпературной высокоэнтальпийной плазмы азота в открытой атмосфере. В качестве источника азотной плазмы использовался плазмотрон постоянного тока с вихревой стабилизацией и расширяющимся каналом выходного электрода $[11,12]$. Обработка образцов проводилась в открытой атмосфеpe c применением азотной плазмы со среднемассовой температурой 4-5kK (далее образец типа I) и 7-9kK (далее образец типа II). По данным [13] можно проанализировать отличие состава плазм (на $\left.1 \mathrm{~cm}^{3}\right)$ : в плазме типа I преобладание молекулярного азота $\mathrm{N}_{2} \sim$ в $10^{4}$; соотношение ионизированных молекул азота $\mathrm{N}^{2+}$ одинаковое в обеих плазмах; в плазме типа II преобладание атомарного азота $\mathrm{N} \sim$ в 10 раз и ионизированных атомов азота $\mathrm{N}^{+} \sim$ в $10^{3}$. Время обработки $1 \mathrm{~min}$. Рентгенограммы снимались на дифрактометре Empyrean фирмы PANalytical (Нидерланды) в геометрии Брэгга-Брентано. Полученные рентгенограммы обрабатывались в программе HighScore Plus (PANalytical), фазовый анализ проводился с помощью базы данных ICSD (PDF-2). Использовалось излучение от медного анода $\left(\mathrm{Cu} K_{\alpha 2}, \lambda=1.54 \AA\right)$. Микроскопические исследования осуществлялись на растровом электронном микроскопе JEOL, оснащенном энергодисперсионным рентгеновским микроанализатором, и атомно-силовом микроскопе Solver Pro-M. Среднеквадратичная шероховатость определялась с использованием программного обеспечения „Nova“, входящего в комплект прибора. Твердость образцов исследовалась с использованием сканирующего нанотвердомера НаноСкан-3D. Значение микротвердости образцов определялось методом динамического индентирования. Величина микротвердости по Виккерсу рассчитывалась усреднением по числу вдавливаний индентора в области $50 \times 50 \mu \mathrm{m}$ с нагрузкой от 1 до $50 \mathrm{mN}$. Анализ гидрофобности поверхности (измерение контактного угла $\vartheta$ ) образцов проводился по методике сидячей капли. Капля воды имела размер порядка $1.5 \mathrm{~mm}$. Измерение контактного угла проводилось по истечении $10 \mathrm{~s}$ после нанесения и достижения неподвижности капли. Оптическая визуализация осуществлялась с помощью цифровой фотокамеры. Ось

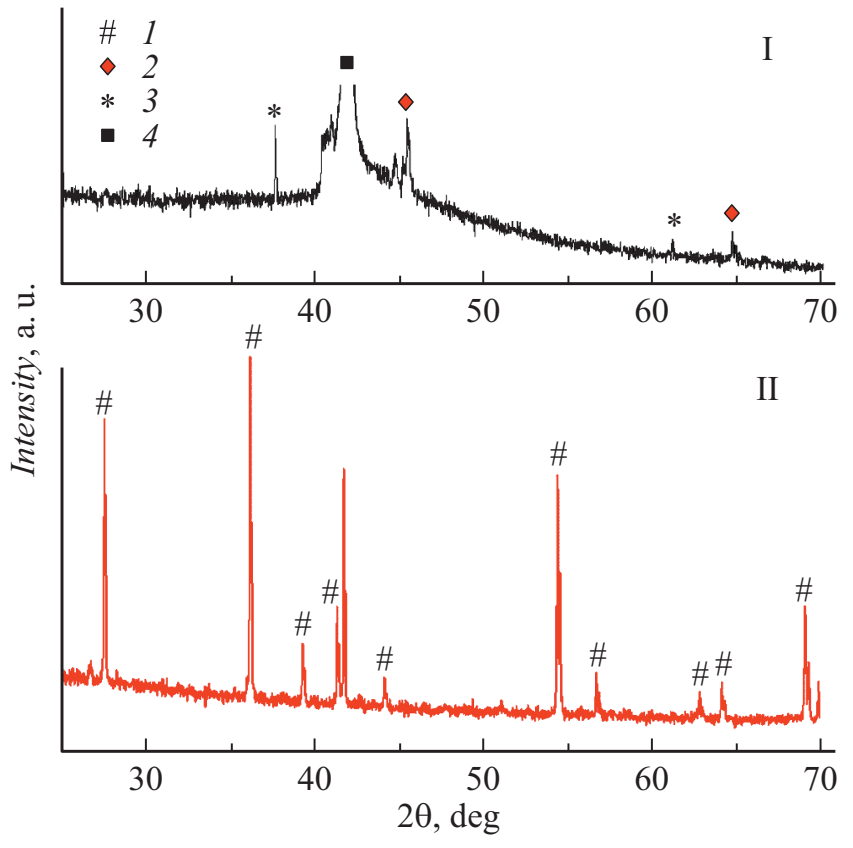

Рис. 1. Рентгенограммы образцов типа I, II. База данных ICSD (PDF-2), номер карточки 98-002-4277. 1 - рутил, 2 - брукит, 3 - анатаз, 4 - сапфир.

объектива камеры размещалась на уровне границы раздела капля воды-поверхность образца. Контактный угол определялся по методике, описанной в [14].

Анализ дифрактограмм, полученных от образцов, представлен на рис. 1. Можно видеть, что образец пленки типа I представляет собой рентгеноаморфный окисленный осадок с возможным присутствием небольшой доли анатаза, брукита. В образце пленки типа II формируется поликристаллическая монофаза рутила. Согласно данным растровой электронной микроскопии (рис. 2), поверхность образца пленки типа I представлена двумя видами структур: ограненные кристаллиты с размерами до микрометра и пористые структуры с округлыми краями. В образце пленки типа II в основном наблюдались ограненные кристаллиты с размерами до нескольких микрометров. По данным энергодисперсионного рентгеновского микроанализа (см. таблицу) содержание азота и кислорода в пленке типа I было значительно ниже, чем в пленке типа II. Образцы также значительно различались по величине шероховатости (см. таблицу). Исследовалась микротвердость путем усреднения по числу вдавливаний индентора в интервале глубин отпечатка 50-200 nm. Для пленок типа I и II были получены значения 25.5 и $27 \mathrm{GPa}$ соответственно. Исследования с применением метода сидячей капли продемонстрировало наиболее интересный результат: при переходе от образца типа I к образцу типа II поверхность меняла свое состояние с гидрофильного $\left(\vartheta=73^{\circ}\right)$ на гидрофобное $\left(\vartheta=120^{\circ}\right)$ (рис. 3$)$.

Полученные результаты свидетельствуют о значительных различиях в процессах окисления и кристалли- 


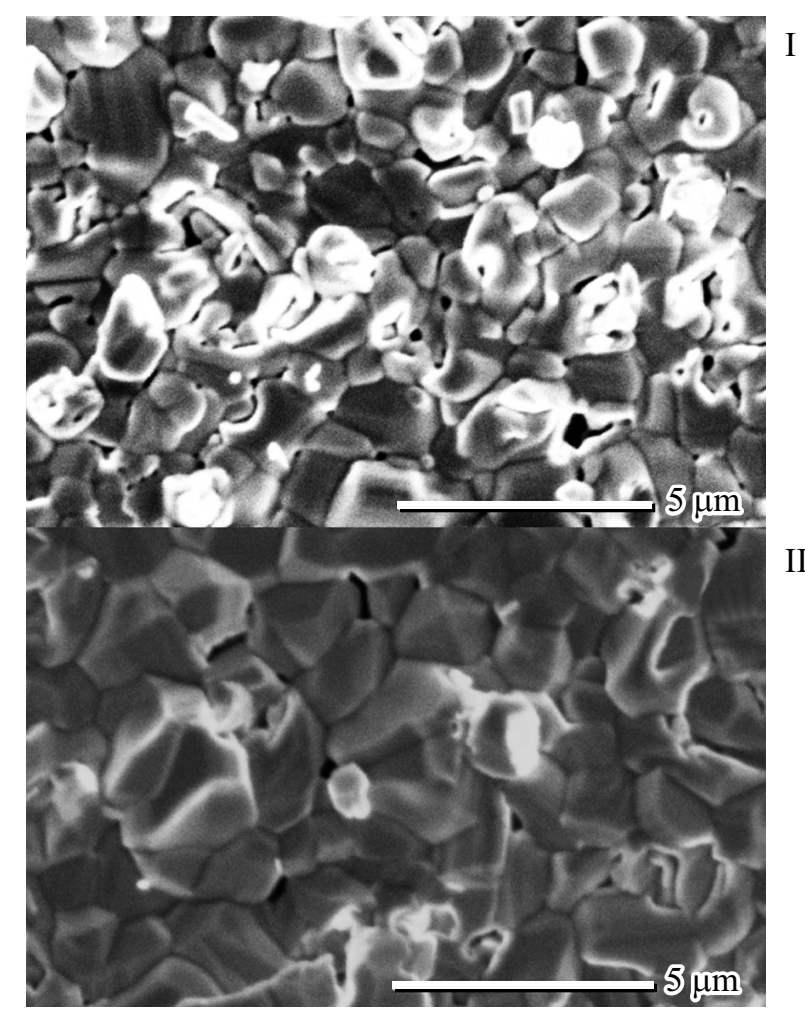

Рис. 2. Электронно-микроскопические изображения поверхности образцов типа I, II.

Соотношение элементов (атомное), шероховатость $\left(R_{q}\right)$, микротвердость $(H)$ пленок азотсодержащего оксида титана на сапфире, обработанных в двух режимах (образцы типа I и II)

\begin{tabular}{l|c|c}
\hline Параметр & Тип I & Тип II \\
\hline $\mathrm{Ti} / \mathrm{N}$ & 4.46 & 1.92 \\
$\mathrm{O} / \mathrm{Ti}$ & 4.94 & 7.34 \\
$R_{q}, \mathrm{~nm}$ & 136.4 & 71.4 \\
$H, \mathrm{GPa}$ & 25.5 & 27
\end{tabular}

зации пленки титана на сапфире в зависимости от условий обработки. Очевидно, при обработке в плазме ионизированных атомов азота все процессы протекают исключительно в твердой фазе. Высокая среднемассовая температура (7-9kK) плазмы способствует быстрому разогреву окружающей атмосферы и, как следствие, высокой активности кислорода наряду с ионизированными атомами азота. Рентгенограмма (тип II на рис. 1) и данные электронной микроскопии (тип II на рис. 2) свидетельствуют о протекании процессов твердофазной кристаллизации в оксидной пленке: достигнута необходимая температура, концентрационное насыщение активным кислородом, высокая диффузионная активность. Реализовать процессы твердофазной кристаллизации с образованием высокоориентированной пленки рутила не удалось, поскольку более длительное проведение плазменной обработки приводило к разрушению подложки.
В свою очередь округлые пористые образования на поверхности образца типа I (рис. 2), обработанного в режиме молекулярной (среднемассовая температура 4-5 kK) плазмы, свидетельствуют о частичном присутствии жидкой фазы. Титан обладает достаточно высокой температурой плавления $\left(1670^{\circ} \mathrm{C}\right)$, однако сравнительно низкая реакционная способность кислорода и молекулярных ионов азота не позволяет пленке титана миновать этап плавления. Отставание процесса окисления от процесса плавления титана и уменьшение плотности титана в жидкой фазе могут объяснить образование пор и каверн в пленке. С наличием такого рода топографических неоднородностей связано увеличение шероховатости пленки типа I по сравнению с шероховатостью пленки типа II (см. таблицу). Данные микроанализа (см. таблицу) свидетельствуют о снижении концентрации кислорода и азота в пленке типа I, что вполне логично, если учитывать низкую реакционную способность газов с молекулярным составом. Обращает на себя внимание отсутствие сильных различий в значениях микротвердости образцов, несмотря на значительное структурно-фазовое, морфологическое отличие. По всей видимости, одной из основных причин увеличения микротвердости покрытия являются внутренние сжимающие напряжения, связанные с особенностью обработки: высокая скорость перемещения фронта окисления от поверхности в глубь покрытия. Следует обратить внимание на увеличение шероховатости при обработке в режиме, соответствующем образцу типа I. Вполне возможно, что в соответствии с моделью Венцеля-Дерягина увеличение шероховатости для гидрофильной поверхности приводит к уменьшению контактного угла. Тем не менее объяснить наблюдаемые результаты только шероховатостью поверхности нельзя, поскольку для радикального изменения свойств поверхности от гидрофильных к гидрофобным требуется изменение самой структуры

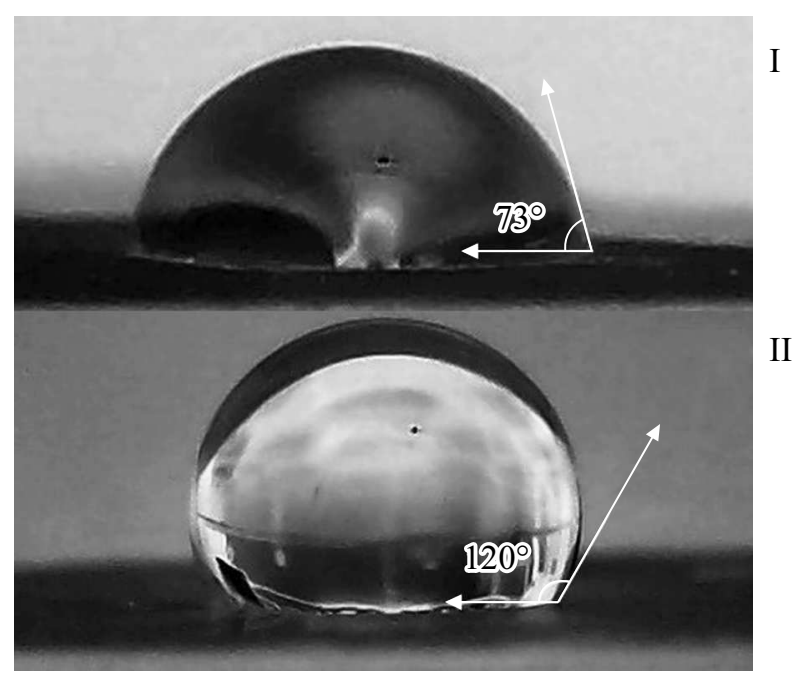

Рис. 3. Зависимость гидрофильных и гидрофобных свойств образцов от условий обработки. 
шероховатости, в частности переход к многомодальной шероховатости. Как показывают исследования, концентрация азота для обоих типов покрытия различается более чем в 2 раза (см. таблицу). Согласно расчетам [15], легирование азотом кластеров $\mathrm{TiO}_{2}$ увеличивает положительную энергию адсорбции Гиббса и гидрофобную составляющую. В целом результаты наших исследований подтверждают выводы, сделанные в [9]: монофазная пленка типа II со структурой рутила отличается высокой гидрофобностью; рентгеноаморфная пленка типа I проявляет гидрофильные свойства. В соответствии с данными [16] кристаллическая монофаза может способствовать формированию на поверхности диоксида титана упорядоченного молекулярного монослоя карбоновых кислот с ярко выраженными гидрофобными свойствами.

Таким образом, в работе изучено влияние состава азотной плазмы при натекании на поверхность в открытой атмосфере на механические и гидрофобные свойства покрытий на основе азотсодержащего оксида титана. Впервые показано, что, управляя составом азотной плазмы, можно формировать либо гидрофильные, либо гидрофобные покрытия на основе азотсодержащего диоксида титана с высокой микротвердостью.

\section{Финансирование работы}

Исследования проводились в рамках выполнения работ по государственному заданию ФНИЦ „Кристаллография и фотоника“ РАН в части характеризации образцов, по государственному заданию ФГБУ ОИВТ РАН в части воздействия плазмы азота, а также при поддержке Российского фонда фундаментальных исследований (грант № 20-0800598). Рентгенофазовый анализ покрытия проводился при частичной поддержке государственного задания FZNZ-2020-0002.

\section{Конфликт интересов}

Авторы заявляют, что у них нет конфликта интересов.

\section{Список литературы}

[1] M.M. Mikhailov, V.V. Neshchimenko, S.A. Yuryev, Rad. Phys. Chem., 121, 10 (2016). DOI: $10.1016 /$ j.radphyschem.2015.12.006Get

[2] J. Heinrichs, T. Jarmar, M. Rooth, H. Engqvist, Key Eng. Mater., 361-363, 689 (2008). DOI: 10.4028/www.scientific.net/KEM.361-363.689

[3] N. Huang, Y.X. Leng, P. Yang, J.Y. Chen, H. Sun, J. Wang, G.J. Wan, A.S. Zhao, P.D. Ding, Nucl. Instr. Meth. B, 242 (1-2), 18 (2006). DOI: 10.1016/j.nimb.2005.08.080

[4] P.P. Karjalainen, W. Nammas, Ann. Med., 49 (4), 299 (2017). DOI: $10.1080 / 07853890.2016 .1244353$

[5] R. Li, T. Li, Q. Zhou, Catalysts, 10 (7), 804 (2020). DOI: $10.3390 /$ catal10070804

[6] М.Х. Гаджиев, Р.М. Эмиров, А.Э. Муслимов, М.Г. Исмаилов, В.М. Каневский, Письма в ЖТФ, 47 (9), 44 (2021). DOI: 10.21883/PJTF.2021.19.51511.18861
[7] Д.А. Жеребцов, С.А. Сюткин, В.Ю. Первушин, Г.Ф. Кузнецов, Д.Г. Клещев, В.А. Герман, В.В. Викторов, А.М. Колмогорцев, А.С. Сериков, ЖНХ, 55 (8), 1271 (2010).

[8] А.Э. Муслимов, А.Ш. Асваров, Н.С. Шабанов, В.М. Каневский, Письма в ЖТФ, 46 (19), 15 (2020). DOI: 10.21883/PJTF.2021.19.51511.18861

[9] M.M. Shirolkar, D. Phase, V. Sathe, J. Rodríguez-Carvajal, R.J. Choudhary, S.K. Kulkarni, J. Appl. Phys., 109 (12), 123512 (2011). DOI: 10.1063/1.3594695

[10] K. Peerawas, T. Abdelhafed, M. Mahamasuhaimi, J. Ausmee, H. Pariyaphan, K. Sakorn, Surf. Interface Anal., 50 (12-13), 1271 (2018). DOI: 10.1002/sia.6518

[11] Э.Х. Исакаев, О.А. Синкевич, А.С. Тюфтяев, В.Ф. Чиннов, TBT, 48 (1), 105 (2010). DOI: $10.31857 / \mathrm{S} 0040364420040031$

[12] М.Х. Гаджиев, А.С. Тюфтяев, А.Э. Муслимов, В.М. Каневский, А.М. Исмаилов, В.А. Бабаев, Письма в ЖТФ, 45 (22), 3 (2019). DOI: 10.21883/PJTF.2019.22.48639.17951

[13] В.Ф. Чиннов, Экспериментальное исследование термической и неравновесной плазмы инертных и молекулярных газов, Докт. дис. (Ин-т высоких температур РАН, М., 2002).

[14] Y. Yuan, T.R. Lee, in Surface science techniques, ed. by G. Bracco, B. Holst. Springer Ser. in Surface Sciences (Springer, Berlin-Heidelberg, 2013), vol. 51, p. 3-34.

[15] O.V. Smirnova, A.G. Grebenyuk, O.P. Linnik, N.O. Chorna, V.V. Lobanov, Scientific papers of NAUKMA, 183, 67 (2016).

[16] J. Balajka, M.A. Hines, W.J.I. DeBenedetti, M. Komora, J. Pavelec, M. Schmid, U. Diebold, Science, 361 (6404), 786 (2018). DOI: $10.1126 /$ science.aat6752 